\title{
Exigência Nutricional de Lisina para Galinhas Poedeiras de Ovos Brancos e Ovos Marrons, no Segundo Ciclo de Produção. 2. Características Produtivas ${ }^{1}$
}

\section{Breno Augusto Campolina Barbosa ${ }^{2}$, Paulo Rubens Soares ${ }^{3}$, Horacio Santiago Rostagno ${ }^{3}$, Martinho de Almeida e Silva ${ }^{4}$, Luiz Fernando Teixeira Albino ${ }^{3}$, Altair Soares das Graças ${ }^{3}$}

RESUMO - O objetivo deste trabalho foi estabelecer as exigências de lisina para galinhas poedeiras de ovos brancos (Lohmann Selected Leghorn [LSL]) e ovos marrons (Lohmann Brown [LB]), no segundo ciclo de produção, da $83^{\mathrm{a}}$ à $98^{\mathrm{a}}$ semana de idade. Foi usado delineamento experimental inteiramente casualizado, com seis repetições e oito aves por unidade experimental. Os tratamentos foram constituídos de um fatorial 2 x 6 (duas linhagens x seis níveis de lisina). As aves foram alimentadas com rações contendo $2860 \mathrm{kcal} \mathrm{EM} \backslash \mathrm{kg}$ de ração, $14,37 \%$ PB e $0,50 \%$ lisina e suplementadas com seis níveis de L-lisina $\mathrm{HCl}$ 98\% (0,00; 0,08; 0,16; 0,24; 0,32; e 0,40\%). Foram avaliados consumo de ração (g/ave.dia), produção de ovos (\%), massa de ovo (g/ave.dia), peso de ovo (g) e conversão alimentar. As poedeiras LSL apresentaram maior produção de ovos e as LB, maior peso médio dos ovos. Produção de ovos, peso de ovo, massa de ovo, conversão alimentar (g/g e $\mathrm{kg} / \mathrm{dz}$ ) foram influenciados pelos níveis de lisina. As exigências nutricionais de lisina para poedeiras LSL e LB foram estimadas, por meio do modelo quadrático, em 0,76 e $0,80 \%$, respectivamente, correspondendo a um consumo de 836 e $880 \mathrm{mg}$ de lisina por ave/dia.

Palavras-chave: exigência nutricional, lisina, poedeiras leves e semipesadas, segundo ciclo de produção

\section{Nutritional Requirements for Lysine in White-Egg and Brwon-Egg Layers in Second Production Cycle. 2. Productive Traits}

\begin{abstract}
This work aimed to establish lysine requirements for white-egg (Lohmann Selected Leghorn) and brown-egg (Lohmann Brown) layers hens in the second producing cycle, from 83 to 98 weeks of age. A completely randomized design with six replicates and eight birds per experimental unit was used. The treatments consisted in a 2 x 6 factorial involving two commercial lines and six lysine levels. The birds were fed diets containing $2860 \mathrm{kcal}$ of ME $/ \mathrm{kg}, 14.37 \% \mathrm{CP}$, and .50\% lysine, supplemented with six levels of L-lysine $\mathrm{HCl} 98 \%(0, .00$, $.08, .16, .24, .32$, and $.40 \%$ ). Feed intake (g/bird/day), egg production(\%), egg mass (g/bird.day), egg weight (g), and feed:egg ratio were evaluated. The white-egg layer hens presented high egg production however and the brown-egg layer lenspresented better results for average egg weight. Egg production, egg weight, egg mass and feed:egg ratio (g/g and kg/dz) were influenced by the lysine level. The nutritional requirements of lysine for eight and brown-egg layer lens were obtained by the quadratic model and estimated in .76 and .80\% for eight and semi white-egg layer hens, respectively, corresponding to 836 and $880 \mathrm{mg}$ of lysine intake by bird/day.
\end{abstract}

Key Words: nutritional requirement, lysine, white-egg and brown-egg layer hens, second production cycle

\section{Introdução}

A muda forçada, prática muito antiga, tem sido utilizada com o objetivo de reduzir os custos de substituição do plantel. MYANO (1993) cita que anualmente 22 milhões de aves são submetidas à muda forçada no Brasil.

OLIVEIRA (1993) relata que existem estudos sobre níveis nutricionais para o segundo ciclo, sendo que as tabelas de exigência e os manuais de marcas comerciais não fazem menções das necessidades para o segundo ciclo de produção. ROSTAGNO et al. (1996) sugerem que novas pesquisas sejam realizadas a fim de se obter melhor conhecimento das exigências de aves em segundo ciclo de postura. Essas aves têm taxas de produção menores que as de primeiro ciclo, produzem ovos maiores, aumentando assim as perdas de ovos, pois o peso da casca não se altera, e ficam, portanto, mais frágeis. Portanto, são justificadas as preocupações com a qualidade externa dos ovos, principalmente, no segundo ciclo de produção.

OLIVEIRA (1992) relata que o nível de proteína total pode influenciar a qualidade da casca após muda forçada, uma vez que aves alimentadas com níveis menores de $\mathrm{PB}$ produzem ovos menores, o que torna a casca mais resistente.

\footnotetext{
${ }^{1}$ Parte da Tese apresentada à UFV, pelo primeiro autor, como parte das exigências para obtenção do título Mestre em Zootecnia. Financiada pelaFAPEMIG.

2Zootecnista e Mestre em zootecnia pela UFV.

${ }^{3}$ Professor da Universidade Federal de Viçosa - Campus UFV - 36571-000 - Viçosa, MG.

${ }^{4}$ Professor da Universidade Estadual do Norte Fluminense - Campos dos Goitacazes, RJ.
} 
A proteína da ração é o que mais onera seus custos. A utilização da proteína depende de vários fatores, entre eles, a composição aminoacítica e a digestibilidade de seus aminoácidos. A formulação de ração com base apenas na proteína bruta pode induzir à subestimação ou superestimação do conteúdo de aminoácidos da ração e, assim, reduzir o desempenho dos animais, além de onerar os custos da ração.

Com o advento da fabricação industrial de lisina (L-lisina.HCl) e metionina (DL-metionina), vários autores têm sugerido a redução do nível de proteína bruta em rações, desde que suplementadas com aminoácidos sintéticos (BLAIR et al., 1976; WEERDEN e SCHUTTE, 1980; e CARMO et al. 1981).

Especial atenção tem sido dada à determinação das exigências de lisina, pois neste aminoácido baseia-se o conceito de proteína ideal, por ser referência para os demais.

Os programas de seleção de poedeiras comerciais as tornam cada vez mais precoces e produtivas, sendo necessária a revisão constante das necessidade nutricionais destas aves, a fim de se estimarem, com maior precisão, seus exigências em aminoácidos.

Portanto, o objetivo desta pesquisa foi estimar as exigências de lisina, para poedeiras comerciais leves e semipesadas no segundo ciclo de produção, no período de 83 a 98 semanas de idade.

\section{Material e Métodos}

O experimento foi realizado na seção de Avicultura do Departamento de Zootecnia, do Centro de Ciências Agrárias da Universidade Federal de Viçosa-MG, no período de 05 de março a 23 de setembro de 1996.

Foram utilizadas 576 poedeiras, submetidas à muda forçada na $76^{\mathrm{a}}$ semana de vida, sendo 288 aves leves da marca comercial Lohmann Selected Leghorn
(LSL) e 288 aves semipesadas da marca comercial Lohmann Brown (LB).

As aves foram alojadas durante o período de produção, em um galpão de postura, de $60 \times 9 \mathrm{~m}$, cercado apenas por telas em suas laterais, coberto com telhas de cerâmica em duas águas, com dois conjuntos de quatro fileiras de gaiolas convencionais cada, separadas por corredor central de $2 \mathrm{~m}$, sendo utilizadas apenas duas fileiras laterais de um dos conjuntos. Durante o período de produção, o fotoperíodo utilizado foi de 16,5 horas por dia.

Após proceder-se à muda e antes de serem submetidas às rações experimentais, as aves foram distribuídas com a finalidade de se padronizarem o peso corporal e a produção de ovos. Posteriormente, esses animais passaram por período de adaptação à ração experimental, de sete dias, seguindo-se o período experimental, que teve a duração de 16 semanas.

As aves tiveram água à vontade em bebedouros de calha de alumínio tipo $\mathrm{V}$, que se encontravam acima do comedouro.

A temperatura do ar e umidade relativa foram obtidas por meio de termômetros de máxima e mínima e termohigrômetro, respectivamente, instalados dentro do galpão à altura das aves. As temperaturas médias e absolutas e a umidade relativa do ar registradas durante o período experimental são apresentadas na Tabela 1.

No início do período experimental as aves tinham 82 semanas de idade, o que corresponde à $6^{\mathrm{a}}$ semana após o início da postura pós-muda forçada; nessa data, as aves leves tinham taxa de postura de $75,50 \%$ e as aves semipesadas, $69,27 \%$.

Foi utilizado o delineamento experimental inteiramente casualisado, com seis repetições e duas marcas comerciais de poedeiras, com oito aves por unidade experimental.

Os tratamentos consistiram de ração basal com

Tabela 1 -Temperatura e umidade relativa média durante o período experimental

Table 1 - Temperature and relative humidity $(R H)$ during the experimental period

\begin{tabular}{|c|c|c|c|c|c|}
\hline \multirow{3}{*}{$\begin{array}{l}\text { Período } \\
\text { (semana) } \\
\text { Period } \\
\text { (week) }\end{array}$} & \multicolumn{4}{|c|}{$\begin{array}{c}\text { Temperatura }\left({ }^{\circ} \mathrm{C}\right) \\
\text { Temperature }\end{array}$} & \multirow[t]{3}{*}{$\begin{array}{l}\text { UR média }(\%) \\
\text { RH mean }\end{array}$} \\
\hline & \multicolumn{2}{|c|}{$\begin{array}{l}\text { Máxima } \\
\text { Maximum }\end{array}$} & \multicolumn{2}{|c|}{$\begin{array}{l}\text { Mínima } \\
\text { Mininum }\end{array}$} & \\
\hline & $\begin{array}{l}\text { Média } \\
\text { Mean }\end{array}$ & $\begin{array}{l}\text { Absoluta } \\
\text { Absolute }\end{array}$ & $\begin{array}{c}\text { Média } \\
\text { Mean }\end{array}$ & $\begin{array}{l}\text { Absoluta } \\
\text { Absolute }\end{array}$ & \\
\hline $1(82-85)$ & 24,6 & 30,5 & 14,1 & 4,5 & 64,11 \\
\hline $2(86-89)$ & 23,7 & 29,5 & 13,2 & 8,0 & 65,54 \\
\hline $3(90-93)$ & 24,3 & 31,0 & 14,6 & 8,0 & 63,12 \\
\hline $4(94-97)$ & 23,6 & 32,0 & 17,1 & 11,5 & 65,21 \\
\hline
\end{tabular}


536 Rev. bras. zootec.

Tabela 2 - Composição percentual da ração basal

Table 2 - Percentage composition of basal diet

\begin{tabular}{|c|c|}
\hline \multicolumn{2}{|l|}{ Ingredient } \\
\hline \multicolumn{2}{|l|}{ Milho } \\
\hline Corn & 69,884 \\
\hline Farelo de soja & 9,496 \\
\hline \multicolumn{2}{|l|}{ Soybean meal } \\
\hline Glúten de milho & 6,672 \\
\hline \multicolumn{2}{|l|}{ Corn gluten } \\
\hline Calcário & 9,408 \\
\hline \multicolumn{2}{|l|}{ Limestone } \\
\hline Fosfato bicálcico & 1,600 \\
\hline \multicolumn{2}{|l|}{ Dicalcium phosphate } \\
\hline $\operatorname{Sal}($ Salt) & 0,362 \\
\hline Amido de milho & 0,400 \\
\hline \multicolumn{2}{|l|}{ Corn starch } \\
\hline Mist. vitamínica ${ }^{1}$ & 0,100 \\
\hline \multicolumn{2}{|l|}{ Vitamim mix } \\
\hline Mist. mineral $^{2}$ & 0,050 \\
\hline \multicolumn{2}{|l|}{ Mineral mix } \\
\hline DL-metionina 99\% (methionine) & 0,069 \\
\hline Cloreto de colina (Choline chloridre) & 0,020 \\
\hline L-Triptofano & 0,022 \\
\hline \multicolumn{2}{|l|}{ L-triptofan } \\
\hline Inerte (Inert) & 1,906 \\
\hline L-lisina $\mathrm{HCl} 198 \%$ & 0,000 \\
\hline Lysine & \\
\hline $\mathrm{BHT}^{3}$ & 0,010 \\
\hline
\end{tabular}

Composição

Composition

\begin{tabular}{|c|c|}
\hline Proteína bruta $(\%)^{4}$ & 14,37 \\
\hline \multicolumn{2}{|l|}{ Crude protein } \\
\hline $\mathrm{EM}(M E), \mathrm{kcal} / \mathrm{kg}^{5}$ & 2860 \\
\hline $\mathrm{Ca}(\%)^{4}$ & 3,990 \\
\hline P total $(\%)^{4}$ & 0,580 \\
\hline \multicolumn{2}{|l|}{ Total P } \\
\hline $\begin{array}{l}\text { Fósforo disponível }(\%)^{5} \\
\text { Available P }\end{array}$ & 0,380 \\
\hline Metionina $(\%)^{5}$ & 0,357 \\
\hline \multicolumn{2}{|l|}{ Methionine } \\
\hline \multicolumn{2}{|l|}{ Digestible methionine } \\
\hline Metionina + cistina $(\%)^{5}$ & 0,620 \\
\hline \multicolumn{2}{|l|}{ Methionine + cystine } \\
\hline Metionina+cistina digestível $(\%)^{5}$ & 0,565 \\
\hline \multicolumn{2}{|l|}{ Digestible methionine + cystine } \\
\hline Lisina (Lysine), $\%{ }^{5}$ & 0,500 \\
\hline Lisina digestível (\%) & 0,439 \\
\hline \multicolumn{2}{|l|}{ Digestible lysine } \\
\hline Treonina $(\%)^{5}$ & 0,545 \\
\hline \multicolumn{2}{|l|}{ Threonine } \\
\hline Triptofano $(\%)^{5}$ & 0,160 \\
\hline \multicolumn{2}{|l|}{ Tryptophan } \\
\hline \multicolumn{2}{|c|}{ 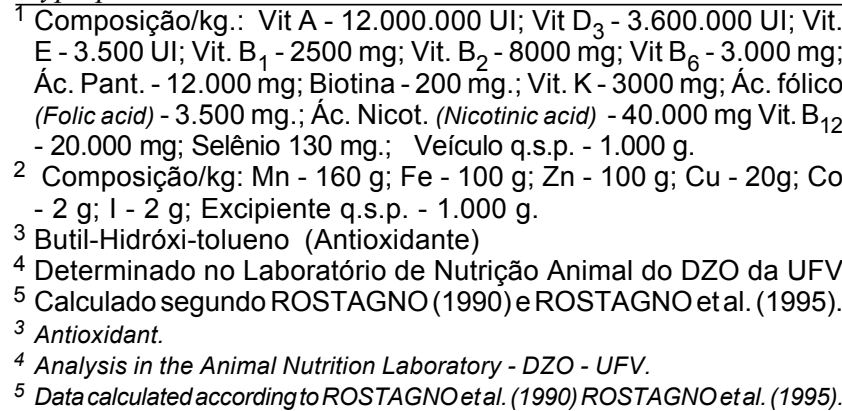 } \\
\hline
\end{tabular}

$14,4 \%$ de proteína bruta $(\mathrm{PB})$, suplementada com seis níveis de Lisina $(0,00 ; 0,08 ; 0,16 ; 0,24 ; 0,32 ; \mathrm{e} 0,40 \%)$, resultando em rações com 0,$500 ; 0,560 ; 0,620 ; 0,680$; 0,740 ; e $0,800 \%$ de lisina.

A ração basal (Tabela 2) foi formulada à base de milho e farelo de soja, para conter $2860 \mathrm{kcal}$ de EM/kg, $14,37 \%$ de PB, $0,620 \%$ de metionina+cistina e $0,500 \%$ de lisina, formulada de modo a satisfazer às exigências nutricionais mínimas, exceto em lisina, segundo as recomendações de ROSTAGNO (1990).

$\mathrm{Na}$ suplementação de lisina, foi utilizada L-lisina $\mathrm{HCl}$ com $98 \%$ de pureza, fornecendo $76,4 \%$ de lisina, em substituição ao amido de milho, ficando, dessa forma, todas as rações isoprotéicas em relação às rações basais com total de $14,4 \%$ de PB. As rações foram fornecidas à vontade durante todo o período experimental.

As características avaliadas foram produção de ovos, massa de ovo, peso médio dos ovos, consumo de ração e conversão alimentar.

Os dados obtidos foram submetidos à análise estatística, utilizando-se o programa SAEG, desenvolvido por EUCLYDES (1983).

\section{Resultados e Discussão}

Observou-se influência dos níveis de lisina sobre a produção de ovos das aves, sendo constatado efeito quadrático e linear $(\mathrm{P}<0,05)$, respectivamente, para poedeiras leves e semipesadas.

Observou-se diferença significativa $(\mathrm{P}<0,05)$ entre médias de produção de ovos das poedeiras leves e semipesadas, sendo as taxas médias de produção, respectivamente, de 72,41 e $66,81 \%$ para poedeiras leves e semipesadas.

As produções médias das poedeiras leves (LSL) e semipesadas (LB), durante o período experimental, em função do nível de lisina da ração, são apresentadas na Tabela 3 .

As poedeiras que receberam suplementação de L-lisina apresentaram maiores taxas de postura, quando comparadas às sem suplementação de L-lisina na ração. As poedeiras leves responderam até o nível $0,680 \%$ de lisina na ração e as poedeiras semipesadas, até o último nível de $0,800 \%$ de lisina, no qual as maiores taxas produção.

GLEAVES e DEWAN (1970) não observaram diferença significativa na produção de ovos, quando utilizaram três níveis de lisina na ração (662, 893 e 1117 $\mathrm{mg}$ ) associado a três de metionina. MORRIS e GOUS (1988) afirmam que a produção e o peso de ovos respondem similarmente ao aumento dos níveis de 
BARBOSA et al.

Tabela 3 - Efeito de diferentes níveis de lisina (Lis) sobre a produção de ovos, o peso médio dos ovos e a massa de ovo em poedeiras de ovos brancos (LSL) e ovos marrons (LB), no segundo ciclo de produção (83 a 98 semanas de idade)

Table 3 - Effect of diferent of levels of lysine (lys) on the egg production, egg weight and egg mass in white-egg (LSL) and brown-egg (LB) layers, in the second cycle of production (from 83 to 98 weeks of age)

\begin{tabular}{|c|c|c|c|c|c|c|}
\hline \multirow[t]{2}{*}{$\begin{array}{l}\text { Nível de lisina (\%) } \\
\text { Lysine level }\end{array}$} & \multicolumn{2}{|c|}{$\begin{array}{c}\text { Produção de ovos }{ }^{2}(\%) \\
\text { Egg production }\end{array}$} & \multicolumn{2}{|c|}{$\begin{array}{c}\text { Peso dos ovos }{ }^{2}(\mathrm{~g}) \\
\text { Egg weight }\end{array}$} & \multicolumn{2}{|c|}{$\begin{array}{l}\text { Massa de ovo }{ }^{2} \text { (g/ave/dia) } \\
\text { Egg mass (g/bird/day) }\end{array}$} \\
\hline & LSL $^{1}$ & $\mathrm{LB}^{1}$ & LSL $^{1}$ & $\mathrm{LB}^{1}$ & $\begin{array}{l}\text { LSL }^{1} \\
\end{array}$ & $\mathrm{LB}^{1}$ \\
\hline$\overline{0,500}$ & 71,45 & 63,58 & 64,86 & 66,62 & 46,31 & 42,28 \\
\hline 0,560 & 73,58 & 66,68 & 66,17 & 67,46 & 48,28 & 43,64 \\
\hline 0,620 & 73,38 & 67,58 & 66,54 & 67,85 & 48,09 & 44,45 \\
\hline 0,680 & 77,83 & 65,68 & 66,76 & 68,77 & 51,46 & 43,23 \\
\hline 0,740 & 68,80 & 66,83 & 68,33 & 68,32 & 47,15 & 45,80 \\
\hline 0,800 & 69,40 & 70,50 & 67,11 & 68,19 & 45,00 & 44,43 \\
\hline Média & $72,41 \mathrm{a}$ & $66,81 \mathrm{~b}$ & $66,63 b$ & $67,87 \mathrm{a}$ & $47,72^{\mathrm{a}}$ & $43,97 \mathrm{a}$ \\
\hline $\mathrm{CV}(\%)$ & & & & & & \\
\hline
\end{tabular}

${ }^{1}$ Efeito quadrático dos níveis de lisina $(\mathrm{P}<0,05)$ pelo teste $\mathrm{F}$.

2 Efeito linear dos níveis de lisina $(P<0,05)$, pelo teste $F$.

3 Médias, na coluna, seguidas por letras diferentes não diferem pelo teste $F(P<0,05)$.

${ }^{1}$ Quadratic effect of lysine levels $(P<.05)$ by $F$ test.

${ }^{2}$ Linear effect of lysine levels $(P<.05)$ by $F$ test.

${ }^{3}$ Means, within a column, followed by different letters do not differ by $F$ test $(P<.05)$.

aminoácidos limitantes e PB da ração, mas, quando o nível está abaixo da exigência, a taxa de postura é mais prejudicada pela deficiência de proteína e aminoácidos.

A menor produção de ovos das poedeiras leves não-suplementadas está de acordo com SCOTT (1961) e CARMO (1981), os quais afirmam que aves suplementadas com aminoácidos sintéticos têm desempenho superior ao de aves não-suplementadas.

Não houve queda da produção de ovos nos níveis mais altos de lisina, para poedeiras semipesadas, ocorrendo efeito linear positivo.

Para poedeiras leves, o NRC (1994) e ROSTAGNO (1990) sugerem níveis maiores de lisina 690 e 703 mg/ave/dia, respectivamente, em rações contendo níveis maiores de $\mathrm{PB}$.

Verificou-se efeito linear $(\mathrm{P}<0,05)$ dos níveis de lisina sobre a massa de ovo para a marca comercial semipesada, enquanto para a marca comercial leve foi observado efeito quadrático $(\mathrm{P}<0,05)$ (Figura 2).

Os valores de massa de ovo obtidos são apresentados na Tabela 3, de acordo com o nível de lisina e a marca comercial das poedeiras. Verifica-se que não houve efeito da marca comercial $(\mathrm{P}<0,05)$ sobre esta característica. As médias de massa de ovo foram 47,72 e 43,97g/ave.dia para poedeiras leves e semipesadas, respectivamente.

MARCH BIELY (1972) obtiveram maior massa de ovo para aves que ingeriram 784 a $840 \mathrm{mg}$ de lisina; aves ingeriram menor quantidade, mesmo com consumo maior de ração, apresentaram menor massa de ovo.

Os valores de peso médio dos ovos são apresentados no Tabela 3, de acordo com o nível de lisina e a marca comercial. Verifica-se que as poedeiras

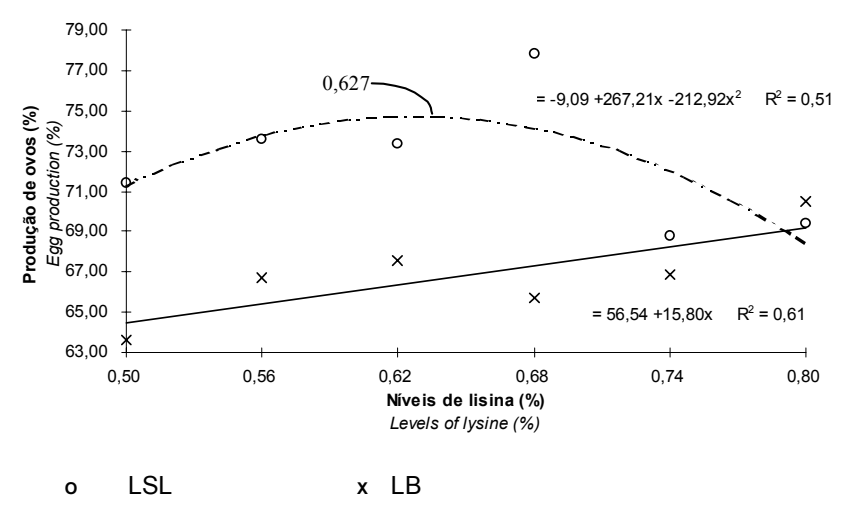

Figura 1 - Efeito dos níveis de lisina sobre a produção de ovos de poedeiras de ovos brancos (LSL) e ovos marrons (LB), no período de 83 a 98 semanas de idade.

Figure 1 - Effect of levels of lysine, on the egg production of whiteegg (LSL) and brown-egg layers, from 83 to 98 weeks to age.

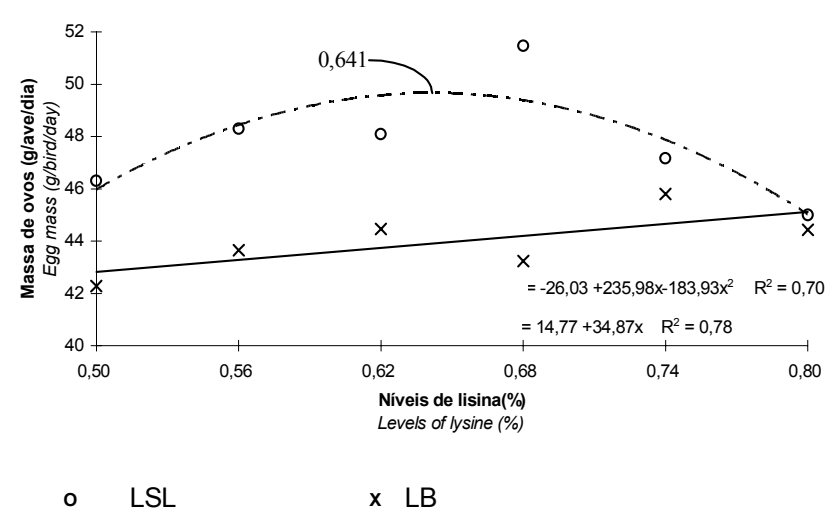

Figura 2 - Efeito dos níveis de lisina sobre a massa de ovo de poedeiras de ovos brancos (LSL) e ovos marrons (LB), no período de 83 a 98 semanas de idade.

Figure 2 - Effect of levels of lysine, on the egg mass of white-egg (LSL) and brown-egg layers, from 83 to 98 weeks of age. 
538 Rev. bras. zootec.

Tabela 4 -Efeito de diferentes níveis de lisina sobre o consumo de ração e a conversão alimentar de poedeiras de ovos brancos (LSL) e ovos marrons (LB), no segundo ciclo de produção (83 a 98 semanas de idade)

Table 4 - Effect of diferent lysine (lys) levels on the feed intake and feed:egg ratio in white-egg (LSL) and brown-egg layer lens (LB), in the second cycle of production (from 83 to 98 weeks of age)

\begin{tabular}{|c|c|c|c|c|}
\hline $\begin{array}{l}\text { Nível de lisina (\%) } \\
\text { Levels of lysine }\end{array}$ & \multicolumn{2}{|c|}{$\begin{array}{c}\text { Consumo de ração (g/ave.dia) } \\
\text { Feed intake (g/bird.day) }\end{array}$} & \multicolumn{2}{|c|}{$\begin{array}{c}\text { Conversão alimentar (g ração/g ovo })^{2} \\
\text { Feed:egg ratio (g diet/g egg) }\end{array}$} \\
\hline 0,500 & 109,50 & 110,00 & 2,372 & 2,615 \\
\hline 0,560 & 112,25 & 111,50 & 2,345 & 2,570 \\
\hline 0,620 & 111,50 & 108,25 & 2,349 & 2,471 \\
\hline 0,680 & 109,75 & 111,50 & 2,139 & 2,628 \\
\hline 0,740 & 110,00 & 108,50 & 2,361 & 2,382 \\
\hline 0,800 & 106,25 & 110,25 & 2,424 & 2,337 \\
\hline Média & $109,86 \mathrm{a}$ & $110,00 \mathrm{a}$ & $2,332 \mathrm{a}$ & $2,501 \mathrm{a}$ \\
\hline
\end{tabular}

Mean

$\mathrm{CV}(\%)$

3,18 5,72

1 Efeito quadrático dos níveis de lisina $(P<0,05)$ pelo teste $F$.

2 Efeito linear dos níveis de lisina $(P<0,05)$ pelo teste $F$.

${ }^{3}$ Efeito não-significativo dos níveis de lisina pelo teste $F(P>0,05)$.

${ }^{4}$ Médias, na coluna, seguidas por letras diferentes, diferem pelo teste $F(P<0,05)$.

${ }^{1}$ Quadratic effect of levels of lysine $(P<.05)$ by $F$ test.

${ }^{2}$ Linear effect of levels of lysine $(P<.05)$ by $F$ test.

${ }^{3}$ Non significative effect of levels of lysine $(P>.05)$, by $F$ test.

${ }^{4}$ Means, within a column, followed by different letters, differ by $F$ test $(P<.05)$.

semipesadas apresentaram maiores pesos dos ovos $(67,87 \mathrm{~g})$ que as poedeiras leves $(66,63 \mathrm{~g})$. Houve efeito quadrático $(\mathrm{P}<0,05)$ dos níveis de lisina para poedeiras leves, o mesmo acontecendo às poedeiras semipesadas, de acordo com a Figura 3.

$\mathrm{Na}$ Tabela 4 são apresentados os consumos de ração das poedeiras leves e semipesadas, em função dos níveis de lisina da ração. Não foi observada diferença significativa, de consumo entre aves leves e semipesadas, com consumos médios de 109,86 e $110 \mathrm{~g} /$ ave.dia, respectivamente.

O consumo de ração não foi influenciado significativamente pelos níveis de lisina, independente da marca comercial, conforme se verifica na Tabela 4.

Para poedeiras leves, o maior consumo diário de $112,25 \mathrm{~g}$ foi observado no nível de $560 \%$, enquanto para poedeiras semipesadas o maior consumo $(111,50 \mathrm{~g})$ foi observado nas aves que receberam ração contendo $0,680 \%$ de lisina, o que eqüivale a $16,17 \mathrm{~g} /$ ave dia de PB.

GLEAVES e DEWAN (1970), JENSEN et al. (1974), LATSAW (1976) também não encontraram influência do nível de lisina sobre o consumo de ração. GLEAVES e DEWAN (1970) afirmam que níveis de metionina, lisina e triptofano influem mais nas características produtivas.

MARCH e BIELY (1972) relatam que rações com deficiência promoveram aumento no consumo com perda de peso. CHI e SPEERS (1976), por sua vez, encontram menor consumo nas aves que tiveram níveis mais baixos deste aminoácido em suas rações.

Os resultados médios obtidos para conversão alimentar g de ração/g de ovo produzido, em função

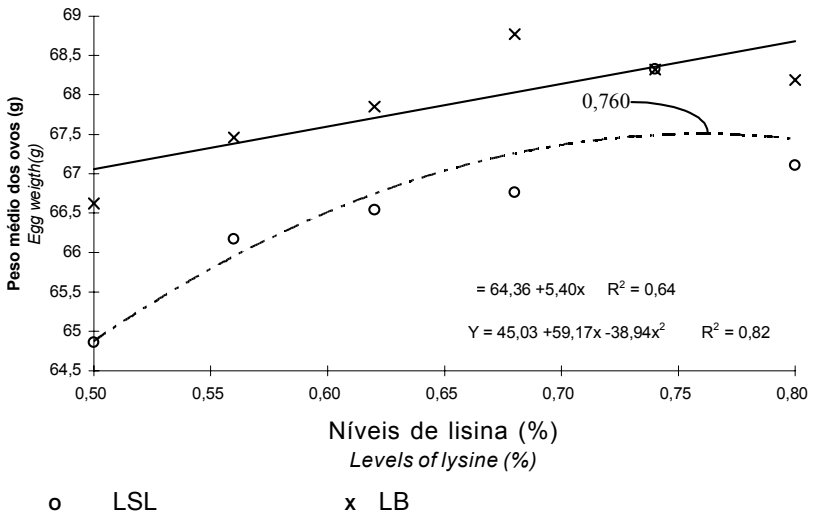

Figura 3 - Efeito dos níveis de lisina sobre o peso médio dos ovos de poedeiras de ovos brancos (LSL) e ovos marrons (LB), no período de 83 a 98 semanas de idade.

Figure 3 - Effect lysine, levels on egg weigth of white-egg (LSL) and brown-egg layers, from 83 to 98 weeks of age.

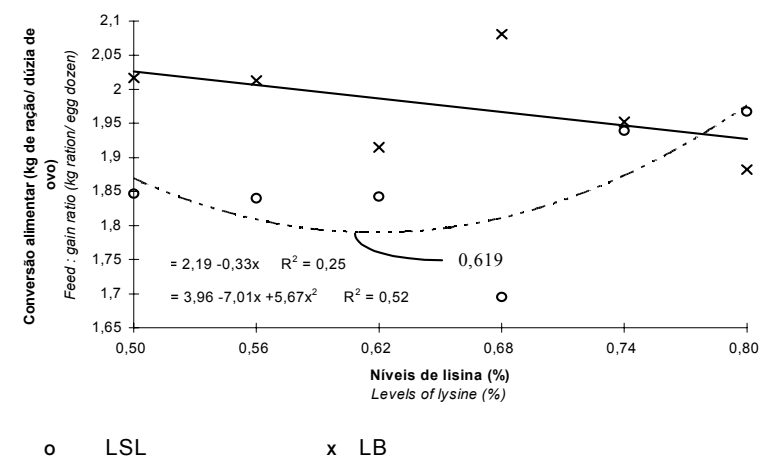

Figura 4 - Efeito dos níveis de lisina sobre a conversão alimentar ( $\mathrm{kg}$ de ração/dúzia ovos) de poedeiras de ovos brancos (LSL) e ovos marrons (LB), no período de 83 a 98 semanas de idade.

Figure 4 - Effect of lysine, levels on the feed:egg dz ratio (kg diet/ egg doozen) of white-egg (LSL) and brown-egg layers, from 83 to 98 weeks of age. 
BARBOSA et al.

Tabela 5 - Regressão das diferentes características em relação ao nível de lisina, para poedeiras de ovos brancos (LSL) e ovos marrons (LB)

Table 5 - $\quad$ Regression of different traits on the lysine levels for white-egg and brown-egg layers

\begin{tabular}{lcc}
\hline & $\begin{array}{c}\text { Poedeiras de ovos brancos } \\
\text { White-egg layers }\end{array}$ & $\begin{array}{c}\text { Poedeiras de ovos marrons } \\
\text { Brown-egg layers }\end{array}$ \\
\hline $\begin{array}{l}\text { Produção de ovos } \\
\text { Egg production }\end{array}$ & $\hat{\mathrm{Y}}=-9,09+267,21 \mathrm{x}-212,92 \mathrm{x}^{2}\left(\mathrm{r}^{2}=0,51\right)$ & $\hat{\mathrm{Y}}=56,54+15,80 \mathrm{x}\left(\mathrm{r}^{2}=0,61\right)$ \\
$\begin{array}{l}\text { Massa de ovo } \\
\text { Egg mass }\end{array}$ & $\hat{\mathrm{Y}}=-26,03+235,98 \mathrm{x}-183,93 \mathrm{x}^{2}\left(\mathrm{r}^{2}=0,70\right)$ & $\hat{\mathrm{Y}}=14,77+34,87 \mathrm{x}\left(\mathrm{r}^{2}=0,78\right)$ \\
$\begin{array}{l}\text { Peso médio dos ovos } \\
\text { Egg weight }\end{array}$ & $\hat{\mathrm{Y}}=45,03+59,17 \mathrm{x}-38,94 \mathrm{x}^{2}\left(\mathrm{r}^{2}=0,82\right)$ & $\hat{\mathrm{Y}}=64,36+5,40 \mathrm{x}\left(\mathrm{r}^{2}=0,64\right)$ \\
$\begin{array}{l}\text { Conversão alimentar }(\mathrm{g} \text { ração/g ovo }) \\
\text { Feed:egg ratio }(\mathrm{g} \text { diet } \mathrm{g} \text { egg })\end{array}$ & $\hat{\mathrm{Y}}=5,00-8,48 \mathrm{x}+6,56 \mathrm{x}^{2}\left(\mathrm{r}^{2}=0,43\right)$ & $\hat{\mathrm{Y}}=3,06-0,86 \mathrm{x}\left(\mathrm{r}^{2}=0,61\right)$ \\
$\begin{array}{l}\text { Conversão alimentar }(\mathrm{kg} \text { ração/dz ovo }) \\
\text { Feed:egg dz ratio }(\mathrm{kg} \text { diet/egg dz) }\end{array}$ & $\hat{\mathrm{Y}}=3,96-7,01 \mathrm{x}+5,67 \mathrm{x}^{2}\left(\mathrm{r}^{2}=0,52\right)$ & $\hat{\mathrm{Y}}=2,19-0,33 \mathrm{x}\left(\mathrm{r}^{2}=0,25\right)$ \\
\hline
\end{tabular}

do nível de lisina para as poedeiras leves e semipesadas, podem ser observados na Tabela 4 .

Não foi observado efeito significativo de marca comercial, sendo obtida conversão alimentar de 2,332 e 2,501 para poedeiras leves e semipesadas, respectivamente.

Houve efeito quadrático $(\mathrm{P}<0,05)$ e linear $(\mathrm{P}<0,05)$ dos níveis de lisina sobre conversão alimentar, respectivamente, para as marcas comerciais leve e semipesada (Figura 5).

$\mathrm{Na}$ Tabela 5 são apresentadas as equações de predição das exigências nutricionais em lisina, determinadas por regressão linear e quadrática, para melhor produção e massa de ovo, peso médio de ovos e conversão alimentar.
A estimativa feita por meio do modelo LRP apresentou menores valores em exigência de metionina+cistina, apesar de apresentar soma de quadrado dos desvios menores (SQD), contudo, observando-se a resposta biológica, constata-se que o LRP quase sempre subestima a dose ótima. Neste experimento, este modelo, por sua vez, estimou a exigência fora dos níveis utilizados. Na Tabela 6, é apresentado resumo das exigências nutricionais em lisina total, digestível e exigência em $\mathrm{mg} / \mathrm{dia}$, para algumas características produtivas.

A exigência de lisina digestível verdadeira foi estimada por intermédio da lisina total e da digestibilidade verdadeira da lisina, segundo

Tabela 6 - Exigência nutricional de lisina para produção, massa, peso médio dos ovos e conversão alimentar para poedeiras de ovos brancos (LSL) e ovos marrons (LB)

Table 6 - Nutritional requirement of lysine for production, egg mass, egg weight and feed:egg ratio to white-egg and brown-egg layers

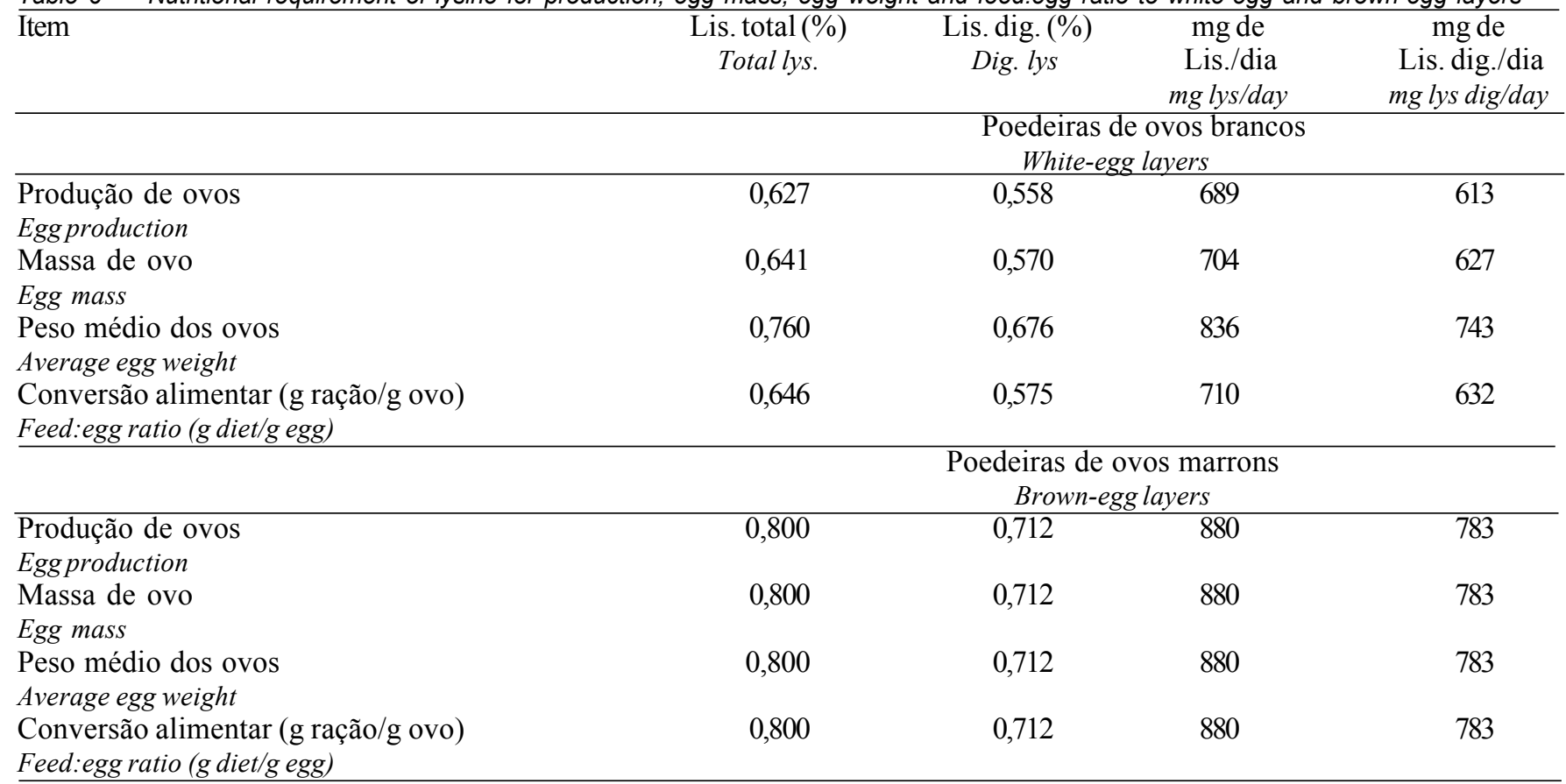




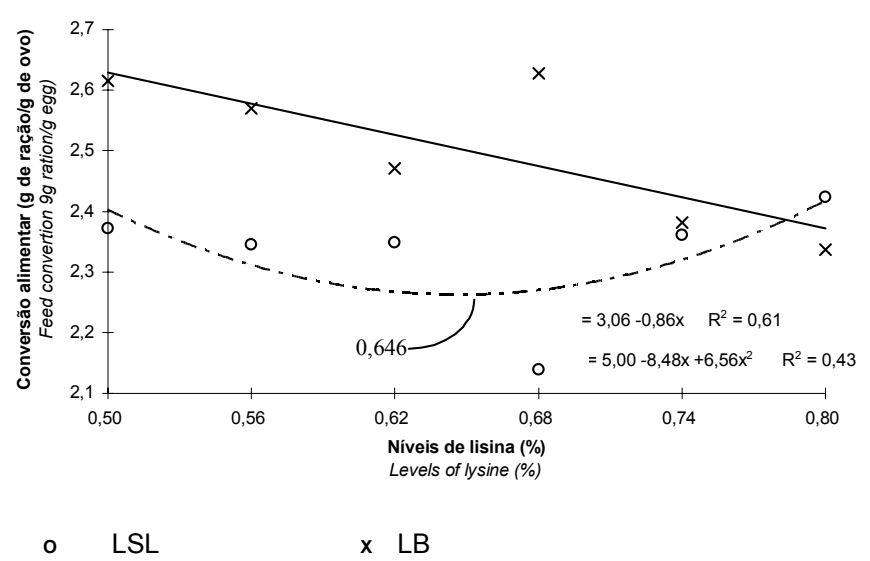

Figura 5 - Efeito dos níveis de lisina sobre a conversão alimentar (g ração/ g ovos produzido) de poedeiras de ovos brancos (LSL) e ovos marrons (LB), no período de 83 a 98 semanas de idade.

Figure 5- Effect of lysine levels on the feed:egg ratio (g diet/ $g$ egg) of white-egg (LSL) and brown-egg layers, from 83 to 98 weeks of age.

ROSTAGNO et al. (1996).

Analisando as respostas de desempenho das poedeiras, considerando as características avaliadas e respeitando o ajuste estatístico, bem como a interpretação biológica, pode-se sugerir, para poedeiras no segundo ciclo de produção de 83 a 98 semanas de idade, exigência de 0,760 e $0,800 \%$ de lisina na ração, correspondendo a consumo de 836 e $880 \mathrm{mg}$ de lisina/ave.dia, para poedeiras leves e semipesadas, respectivamente.

Com base na lisina digestível, as poedeiras leves requerem $0,676 \%$ de lisina digestível na ração e as semipesadas, $0,712 \%$ de lisina digestível na ração, correspondendo a consumos de 744 e $783 \mathrm{mg}$ de lisina digestível/ave/dia, para poedeiras leves e semipesada, respectivamente. Como foi observado, os níveis utilizados para as poedeiras semipesadas parecem estar abaixo do ideal das exigência das mesmas, sendo, portanto, aconselhável a utilização de níveis maiores a fim de verificar se não haveria resposta com a utilização destes níveis maiores.

Os níveis encontrados neste trabalho são superiores aos propostos por GOULART (1997), ROSTAGNO et al (1996), ZOLLITSCH et al. (1996) e NRC (1994), que utilizaram poedeiras em primeiro ciclo; os níveis encontrados no Brasil foram sempre superiores aos encontrados no exterior.

\section{Conclusões}

As exigências nutricionais de lisina para poedeiras leves e semipesadas foram obtidas por meio do modelo quadrático e, respeitando-se a interpretação biológica, estimadas em 0,760 e $0,800 \%$ para poedeiras leves e semipesadas, respectivamente, correspondendo a consumo de 836 e $880 \mathrm{mg}$ de lisina por ave/dia.

\section{Referências Bibliográficas}

BLAIR, R., LEE, D.J., FISHER, C. et al. 1976. Response of laying hens to a low-protein diet supplemented whit essential amino acids, L-glutamic and/or intact protein. Br. Poult. Sci., 17:427-440.

CARMO, M.B. 1981. Níveis de proteína e de aminoácidos sulfurosos em rações de galinhas poedeiras sob regime de alta temperatura. Viçosa, MG:UFV,1981. 104 p. Dissertação (Mestrado em Zootecnia) - Universidade Federal de Viçosa.

CHI, M.S., SPEERS, G.M. 1976. Effects of protein and lysine levels in layer diets. Poult. Sci., 54(5):1746-1747.

EUCLYDES, R.F. 1983. Manual de utilização do programa SAEG (Sistema para Análise Estatística e Genética). Viçosa, MG: UFV, 59p.

GLEAVES, E.W., DEWAN, S. 1970. Influence of methionine, lysine and tryptophan upon food intake and production response in laying chickens. Poult. Sci., 49:1687-1692.

GOULART, C.C. 1997. Exigência nutricional de lisina para poedeiras leves e semipesadas. Viçosa, MG:UFV, 1997. 52p. Dissertação (Mestrado em Zootecnia) - Universidade Federal de Viçosa.

JENSEN, L.S., CHANG, C.H., FALEN, L. 1974. Response to lysine supplementation by laying hens fed practical diets. Poult. Sci., 53:1387-1391.

LATSHAW, J.D. 1976. Lysine requeriments of hens fed diets whith corn as the major ceral grain. Poult. Sci., 55:2348-2353.

MARCH, B.E., BIELY, J. 1972. The effects of protein level and amino acid balance in wheat-basead laying rations. Poult. Sci., 51:547-557.

MORRIS, T.R., GOUS, R.M. 1988. Partitioning of the response to protein between egg number and egg weight. Br. Poult. Sci., 29(1):93-99.

MYANO, O.A. 1993. Viabilidade econômica da muda forçada em poedeiras comerciais. In: CONFERÊNCIA APINCO DE CIÊNCIA E TECNOLOGIA AVÍCOLAS, Santos, 1993. Anais... Campinas: FACTA, p.159-166.

NATIONAL RESEARCH COUNCIL - NRC. 1994. Nutrient Requirements of Poultry. 9. ed. Washington, D.C., National Academy Press, 155p.

OLIVEIRA, B.L. 1992. Pontos críticos do manejo de poedeiras. In: CONFERÊNCIA APINCO DE CIÊNCIA E TECNOLOGIA AVÍCOLAS, 5, 1992, Santos. Anais...Campinas: FACTA, p.137-144.

OLIVEIRA, B.L. 1993. Alimentação de poedeiras leves após muda forçada. In: SIMPÓSIO LATINO AMERICANO DE NUTRIÇÃO DE AVES, 1993, Campinas. Anais... Campinas: CBNA, p.46-50.

REID, B.L. 1976. Estimated daily protein requirements of laying hens. Poult. Sci., 55:1641-1645. 
BARBOSA et al.

ROSTAGNO, H.S. Valores de composição de alimentos e exigência nutricional utilizadas na formulação de rações para aves. In: REUNIÃO ANUAL DA SOC. BRAS. DE ZOOT., (Avicultura) Piracicaba: Anais... Piracicaba: FEALQ. 1990. p.11-30.

ROSTAGNO, H.S., BARBARINO JR, P., BARBOZA, W.A. 1996. Exigência nutricional das aves determinadas no Brasil. In. SIMPÓSIO INTERNACIONAL SOBRE EXIGÊNCIAS NUTRICIONAIS DE AVES E SUÍNOS. 1996. Viçosa. Anais... Viçosa: UFV, p.361-388.

SCOTT, M.L. 1961. Will better amino acid balance improve efficiency of egg production? Feedstuffs, 33:17.

WEERDEN, E. J. V., SCHUTTE, J.B. 1980. Lysine requeriments of the laying hen. Archieve Geflugelk, 44(1):36-40.
ZOLLITSCH, W., CAO, Z., COON, G. et al. 1996. Nutrients requirements of laying hens. In: SIMPÓSIO INTERNACIONAL SOBRE EXIGÊNCIAS NUTRICIONAIS DE AVES E SUÍNOS, 1996, Viçosa, MG. Anais... Viçosa, MG: UFV, p.109-159.

Recebido em: 12/02/98

Aceito em: 03/11/98 